\title{
Inquiry, knowledge and understanding
}

\section{Christoph Kelp ${ }^{1}$}

Received: 1 September 2017 / Accepted: 1 May 2018 / Published online: 30 May 2018

(C) The Author(s) 2018

\begin{abstract}
This paper connects two important debates in epistemology - to wit, on the goal of inquiry and on the nature of understanding - and offers a unified knowledge-
\end{abstract} based account of both.

Keywords Knowledge $\cdot$ Understanding · Inquiry · Epistemology

\section{Introduction}

We are inquiring minds. When we do inquire, we may inquire into specific questions such as the question as to whether Napoleon was French. However, we may also inquire into general phenomena such the life of Napoleon.

Inquiry is a goal directed activity. This means that inquiry has a success condition, a condition under which its goal has been reached.

I take the following to be highly plausible theses about the goal of inquiry into, respectively, specific questions and general phenomena:

Inquiry, Question. When you inquire into a certain question, you aim to settle that question and your inquiry is successful if and only if you settle that question.

Inquiry, Phenomenon. When you inquire into a certain phenomenon, you aim to understand that phenomenon and your inquiry is successful if and only if you understand that phenomenon.

In what follows, I will assume without further argument that these two theses are true.

Christoph Kelp

christoph.kelp@glasgow.ac.uk

1 Department of Philosophy, University of Glasgow, 67-69 Oakfield Ave, Glasgow G12 8LP, UK 
At the same time, there is a lively debate in the epistemological literature on the goal of inquiry into specific questions. The main candidates here are that the goal of inquiry is true belief (TB-Goal), justified belief (JB-Goal), justified true belief (JTB-Goal), or knowledge (K-Goal). ${ }^{1}$ Given Inquiry, Question, these can be viewed as competing accounts of what it takes to settle a question.

The first aim of my paper is to offer a couple of arguments for K-Goal (Kelp 2014, 2017a) and so concerns inquiry into specific questions. The remainder of the paper, in contrast, is about inquiry into general phenomena and understanding. Given Inquiry, Phenomenon, we can derive more substantive conditions on success in inquiry of phenomena from more substantive accounts of understanding. My central aim here is to gather further support for an account of understanding I have developed elsewhere (Kelp 2015). More specifically, I will first argue that my account makes for a better fit with Inquiry, Phenomenon than the competition and so scores further points against it. While I stated my account of understanding in terms of knowledge, the 2015 paper did not motivate a distinctively knowledge-based version of the account. The last aim of this paper is to remedy this defect: I will show that the argument for K-Goal can be extended to provide support for a distinctively knowledge-based version of my account of understanding.

\section{The goal of inquiry}

According to Inquiry, Question, when you inquire into a certain question, your aim to settle that question and attain success in your inquiry into a certain question if and only if you have settled that question. There is a sense of 'settling a question' on which you settle a given question only if you settle it for all humanity. This is not the sense at issue here as the resulting requirement is too strong. After all, your inquiry into the question as to whether climate change is happening, say, can be successful even if it doesn't serve to settle it for die hard climate change deniers. Rather, all that's required for you to settle a given question is that you settle it for yourself. While this avoids imposing too strong a requirement on success in inquiry, it now threatens to be too weak. After all, die hard climate change deniers may settle the question whether climate change is happening for themselves (in the negative) without thereby attaining success in their inquiries. What is needed in addition is that you settle your question properly. Here, then, is how the above claim is to be read:

Inquiry, Question*. You have attained success in your inquiry into a certain question if and only if you have properly settled that question for yourself.

Consider, next, the following plausible thesis about belief:

Belief. You have a belief on a certain question if and only if you have settled that question for yourself.

\footnotetext{
${ }^{1}$ K-Goal is defended e.g. in Kelp (2014, 2017a), Millar (2011) and Williamson (2000), TB-Goal e.g. in Kvanvig (2003) and Lynch (2005) and JB-Goal e.g. in Davidson (2005), Feldman (2002) and Rorty (1995, 2000).
} 
Some even go so far as to accept Belief as an account of the nature of belief. ${ }^{2}$ For present purposes, it's not necessary to embrace so strong a claim. All I need is that it is a truth about belief, whether or not it also captures its essence.

But now note that Inquiry, Question and Belief jointly entail that you have attained success in your inquiry into a certain question if and only if you have a proper belief on that question. But, of course, a proper belief is a belief that satisfies the norm of belief. In other words, we get the following result:

Coincidence Thesis. The success condition for inquiry coincides with the compliance condition for the norm of belief.

Finally, recall the list of live candidates in the literature on the goal of inquiry into specific questions: TB-Goal, JB-Goal, JTB-Goal and K-Goal. Given Coincidence Thesis, it is no surprise that all four should be on the list of candidates. After all, all of these views are also plausible candidates for the norm of belief and most, if not all, of them have been defended as such. ${ }^{3}$ More interestingly, however, it also explains why the list of candidates should not be longer. After all, other candidates would appear either too weak or too strong to be plausible candidates for the norm of belief. Blameless belief, for instance, would be too weak because one can violate norms blamelessly, including the norm of belief. Understanding why and certainty, on the other hand, would be too strong because one can have a proper belief on a certain question even though one does not understand why $p$ and isn't certain that $p$. For instance, one's belief that $p$ may be a proper belief on the question whether $p$ even though one doesn't have a belief on why $p$ and so doesn't understand why $p$ and even though one is not certain that $p$. The fact that these four are the live candidates in the debate is thus entirely as it should be.

With this point in play, I'd now like to give two arguments in favour of K-Goal. Here is the first:

One can be committed to attaining successes in goal-directed activities. There are various types of such commitment one may have incur. The nature of the commitment depends on how it arises. For instance, one may have promised someone to reach it. In this case, one's commitment will be moral in nature. Alternatively, one may have been contracted to reach it in which case one has a contractual commitment. Other kinds of commitment are conceivable and one may simultaneously have various different kinds of commitment.

Most importantly for present purposes, one way in which one can be released from any commitment one may have towards attaining success in a goal-directed activity is by actually pulling off the feat, i.e. by scoring the success. This gives us the following first crucial thesis about goal-directed activities:

Commitment Release. If, at $t$, one attains success in a given goal-directed activity, then, at $t$, one is released from all commitments towards attaining that success.

Now consider the following case:

\footnotetext{
2 See Hieronymi (2009) which also makes a convincing case for this claim.

3 The knowledge norm of belief is defended e.g. in Williamson (2000), the truth norm e.g. in Wedgwood (2002) and the justification norm e.g. in Feldman (2000).
} 
The Hire. You are a private detective. I have hired you for up to one month to find out whether $(C=)$ my wife is cheating on me with someone from work. Fortunately for you, you very quickly acquire very strong evidence in support of $C$. You see my wife going into and out of the house of her colleague $X$ at night, accumulate a number of testimonials stating to have witnessed the romantic involvement of my wife with $X$ and, finally, you are provided with relevant photographic evidence by one of the witnesses. On the basis of this evidence, you come to believe that $C$. When you come knocking on my door to collect your money, you find me gone. Rather than wait around for me, you decide to go on holiday in the Caribbean and to collect the money later. Whilst you are sipping cocktails in the sun and before the month is up, it becomes widely known that the evidence in support of my wife's cheating is misleading. In fact, a number of colleagues were trying to get back at her, say because she was responsible for implementing a very unpopular policy at work. You, of course, are entire unaware of all this. At the same time, unbeknownst to everyone involved in the revenge campaign, my wife did have an affair with one her colleagues, $Y$.

Notice that your belief that $C$ was formed on the basis of excellent evidence, evidence that is strong enough to ensure that your belief that $C$ is justified. In addition, it is true: someone from work did indeed have an affair with my wife. It is just that it was not $X$ but $Y$. That means that you have a justified true belief that $C$. According to three out of the four live candidates in the debate on the goal of inquiry-to wit, TB-Goal, $J B$-Goal and JTB-Goal-you have reached the goal state of your inquiry into whether $C$. In conjunction with Commitment Release, these views predict that you are released from all commitments towards settling the question whether $C$.

Now here is the key question: Is this prediction correct? In particular, are you released from your contractual commitment to settle the question whether $C$ ? No. As far as your contract is concerned, what you ought to be doing is work on the case rather than sit on the beach in the Caribbean. To see this, put yourself in my shoes (i.e. in the shoes of your employer). Suppose I just found out about your situation. While I might concede that you have an excuse for no longer working on the case, I could rightly insist that you go back to work and fulfil your contract. Crucially, there is no need to negotiate a new contract with you. The old contract is still binding. None of this would make any sense if you had been released from your contractual commitment. Thus, the prediction that you are released from all commitments towards settling the question whether $C$, which each of TB-Goal, JB-Goal and JTB-Goal generates in conjunction with Commitment Release, is mistaken.

In contrast, $\mathrm{K}$-Goal does not make a mistaken prediction here. After all, the case is a standard Gettier case and so your belief falls short of knowledge. According to $K$-Goal, then, you do not attain success in the inquiry into whether C. K-Goal therefore does not predict that you are released from your contractual commitment to settling the question you were employed to settle. Since $K$-Goal is the only live candidate in the debate on the goal of inquiry that does not make mistaken predictions, there is reason to think that $K$-Goal is true.

Let's move to the second argument. We may place rewards on attaining successes in goal directed activities. For instance, suppose I offer a million bucks for bringing me 
Jesse James's head. When this happens, you will be entitled to any reward so placed if and only if you attain the relevant success. For instance, you will be entitled to the million bucks I placed on bringing me Jesse James's head if and only if you bring me Jesse James's head. This gives us the following principle:

Reward Entitlement. If there is a reward on scoring a success in a given goal-directed activity, then you are entitled to this reward if and only if you score the relevant success.

Now consider the following case:

The Reward. I offer a reward of ten thousand bucks to the first to find out whether $C$. The first person to claim the reward tells me that the answer is yes. He saw my wife going into and out of $X$ 's house at night, offers a number of testimonials stating to have witnessed the romantic involvement of my wife with $X$ and, finally, provides relevant photographic evidence. Meanwhile, it becomes widely known that this evidence is misleading and the result of a revenge campaign against my wife. The second person to claim the reward, who arrives just a bit later, also tells me that the answer is yes. She has a videotape of my wife in a romantic embrace with the other colleague $Y$ and actually brought her along to confess her digressions.

Who should get the money? It is intuitively clear that the answer is: the second person. However, between the four live candidates in the literature, only K-Goal can secure this result. To see why, note that the first person's case is another textbook example of a Gettier case: he has a justified true belief that $C$ that falls short of knowledge. Since he has a justified true belief that $C$, TB-Goal, JB-Goal and JTBGoal all predict that he has attained success in inquiry into the question whether $C$. And since he was the first to do so, by Reward Entitlement, these views are firmly committed to the claim that he is entitled to the money. But of course that's the wrong result. In contrast, K-Goal predicts the right result. Since the first person is gettiered, he does not know. So, by K-Goal, he has not attained success in the relevant inquiry and so isn't entitled to the money. The second person, in contrast, does come to know the answer. In conjunction with Reward Entitlement, K-Goal predicts, correctly, that she should get the money. By the same token, there is further reason to believe that K-Goal is true.

What comes to light, then, is that there is reason to think that when you inquire into a certain question, you aim to come to know the answer. While this is a nice result about the goal of inquiry into specific questions, it is somewhat limited in scope. After all, it remains silent on what the goal of inquiry into general phenomena might be. This is the question I will take up in what follows.

\section{Understanding: the true account}

Recall the plausible thesis about the goal of inquiry from the introduction:

Inquiry, Phenomenon. When you inquire into a certain phenomenon, you aim to understand that phenomenon and your inquiry is successful if and only if you understand that phenomenon. 
Given Inquiry, Phenomenon, we can unpack the goal of inquiry into general phenomena by taking a closer look at the nature of understanding. Now, there are two main accounts of understanding in the philosophy of science literature. According to explanationists, understanding is in essence knowledge of correct explanations (Hempel 1965; Salmon 1984; Khalifa 2012, 2013). Manipulationists, on the other hand, claim that understanding is essentially a specific kind of ability, roughly, an ability to perform (certain kinds of) manipulations of (certain kinds of) representations of the phenomena understood (de Regt and Dieks 2005; de Regt 2009a, b; Grimm 2006, 2014; Wilkenfeld $2013 .^{4}$

In a recent paper (Kelp 2015), I argue that both types of accounts remain ultimately unsatisfactory and propose a better alternative. In a nutshell, the reason why explanationism fails is that one can acquire understanding without coming to know explanations. For instance, one can understand the independence of gravitational acceleration from mass by appreciating Galileo's famous thought experiment without thereby coming to know an explanation of why gravitational acceleration is independent of mass (Lipton 2009). Manipulationism, in contrast, struggles with cases in which agents know a lot about a phenomenon but do not have the relevant abilities to manipulate representations in the relevant ways-think, for instance, of severely dyslexic agents. Here is the alternative I propose, which, for want of a better label, I will henceforth refer to as the true account:

Maximal Understanding. If one has fully comprehensive (and maximally wellconnected) knowledge a phenomenon $P$, then one has maximal understanding of $P$.

Degrees of Understanding. Degree of understanding of $P$ is a function of distance from fully comprehensive and maximally well-connected knowledge of $P$ : the closer one approximates fully comprehensive and maximally well-connected knowledge of $P$, the higher one's degree of understanding of $P$.

Outright Understanding. " $S$ understands $P$ " is true in context $c$ if and only if $S$ approximates fully comprehensive (and maximally well-connected) knowledge of $P$ closely enough to be such that $S$ would (be sufficiently likely to) successfully perform any task concerning $P$ determined by $c$, if, in addition, $S$ were to have the skills needed to do so and to exercise them in suitably favourable conditions.

The true account can steer clear of the problems the competition encounters on both sides. Since one can come closer to fully comprehensive knowledge of a phenomenon without coming to know an explanation of it, the true account can allow for understanding without knowledge of explanations. This is just what happens in the case of someone who understands the independence of gravitational acceleration and mass by appreciating Galileo's thought experiment. Moreover, on this account, understanding simply does not require abilities to manipulate representations either. All that's required is knowledge. Since dyslexic agents may have the relevant knowledge with-

\footnotetext{
4 What about accounts in the epistemology literature such as Kvanvig's (2003, 2009) and Elgin's (1996, 2006, 2009)? It might be thought that they don't neatly fit into either camp. Accordingly, shouldn't they be discussed separately? While I agree that they should, I have already done so elsewhere in more detail (Kelp 2017b), which is why I will set them aside here.
} 
out being able to manipulate representations, the true account can allow that they have understanding as well.

\section{The true account scores further}

With Inquiry, Phenomenon and the true account in play, let's think about the relation between understanding, as the true account construes it, and the goal of inquiry. In particular, note that the true account has some further nice features:

First, the true account fits very nicely with Inquiry, Phenomena. To see why, note first that phenomena are very plausibly associated with a set of true propositions that describes them and embeds them in a broader nexus of phenomena (Kelp 2015). On the above view of understanding, inquiry into general phenomena aims at knowledge of the associated true propositions.

Second, the true account serves to deliver an appealingly unified account of Inquiry, Question and Inquiry, Phenomena. To see why, recall that inquiry into specific questions aims at knowledge of the answer. But the answer is a true proposition that's associated with the question. So, on the true account, inquiry into specific questions and into general phenomena share a common core: both aim at knowledge of the associated true propositions.

Third, the true account can offer an appealing account of progress in inquiry: roughly, progress in inquiry into a phenomenon consists in coming to know more true propositions about it. For instance, if you set out to inquire into the life of Napoleon and you come to know that Napoleon was French, you make progress in your inquiry. The above account can easily account for this.

It may also be worth noting that, as a result, the true account once again does better than its explanationist and manipulationist rivals. Unlike its manipulationist rival, the true account achieves a unified account of Inquiry, Question and Inquiry, Phenomena in terms of knowledge. In contrast, according to manipulationists, inquiry into specific questions and inquiry into general phenomena have entirely different aims. One aims at knowledge, the other at an ability to manipulate representations. Since unification is a theoretical virtue, that means that there is further reason to favour the true account.

And while explanationism can of course achieve unity here as well, it will struggle to offer an equally attractive account of progress in inquiry into general phenomena. The reason for this is that it looks as though one can make progress in inquiry into a general phenomenon by acquiring non-explanatory knowledge. Coming to know that Napoleon was French is a case in point here. (Note that manipulationism will also do worse than the true account on this front.)

In this way, then, thinking about the goal of inquiry serves to provide further support for the true account vis-à-vis its most prominent rivals.

\section{The true account as a knowledge-based account}

However, there remains at least one fly in the ointment. For my account to be preferable to the competition, it is not necessary to assume that understanding is a form of knowledge. To see this, just note that all of the original advantages will remain even if 
we replace all occurrences of 'knows' and its cognates by 'truly believes', 'justifiably believes' or perhaps 'justifiably and truly believes'.

True, in order to attain a unified account of inquiry into specific questions and inquiry into general phenomena, the true account will have to analyse understanding in terms of knowledge. However, this will give us at best a very weak reason to do so. It would be nice to have some independent reason to think that the true account is indeed best unpacked in terms of knowledge.

Fortunately, this can be done. More specifically, it is possible to extend the arguments for K-Goal to argue for a distinctively knowledge-based version of the true account. To see how, consider first the following case:

The Reward 2. I offer a reward of a million bucks to the first to uncover the full story of my wife's affair with $Y(=P)$. The first person to claim the reward offers a full account of $P$ that is based on a recent DEA report he was able to access. (The DEA got interested in this as part of an investigation of the drug business that my wife and $Y$ were running on the side.) Meanwhile, and unbekownst to this person, I have come to know that the DEA report is a fabrication of a corrupt agent who wanted to climb the career ladder. At the same time, incredible as though this may sound, by an enormous stroke of luck, everything the report states about $P$ is true. The second person to claim the reward, who arrives just a bit later, offers me an equally detailed account that is the result of scrupulous and careful research.

Who should get the money? Again, it is clear that the answer is: the second person. The fabricated report simply doesn't afford the first person cognitive access to the phenomenon and so doesn't afford her understanding of it either. ${ }^{5}$

However, again, the only way to secure that result is if we take success in inquiry to require knowledge. To see why, note that the first person's case is an elaborate Gettier case: while the DEA report was fabricated, everything it states about $P$ is true. But since all of his beliefs are justified and true, if we accept Inquiry, Phenomena and we analyse understanding along the lines proposed by the true account with the exception that we replace all occurrences of 'knows' by 'justified and/or true belief', the result we will get is that the first person did attain success in inquiry into $P$. And since he was the first to do so, by Reward Entitlement, we are now firmly committed

\footnotetext{
5 This is pace Hills (2016) who claims that gettierisation does not preclude understanding and so will likely claim that understanding is present in this case. I must confess that I find it wildly implausible that fabrication can generate understanding. Consider cases in which it is not even known that there is a phenomenon out there in the world that corresponds to the fabrication. For instance, suppose someone fabricates and comes to believe a story about the lives of a colony of marine pygmy elephants which live at the bottom of the Pacific (Kelp 2015). I take it to be pretty clear that this person does not come to understand the lives of the pygmy elephants even if, incredibly as though it may be and unbeknownst to all of us, there actually exists such a colony and their lives are exactly as this person believes them to be. (And if he tells another person about this who comes to believe story as well and connects the beliefs in just the same way, this person also doesn't understand it.) Why? Because the beliefs bear no connection to the mind-independent phenomenon. The fabrication does not put the agent in touch with the phenomenon. It does not afford him cognitive access to it. And, of course, fabrication does not give us cognitive access/understanding here, then there is every reason to think that it won't do so in the case I am discussing. Now, anyone who thinks that, in this case, the person does understand the lives of the colony of pygmy elephants will not be convinced by this. However, I find the thought that she does understand so implausible that I have little more to offer in response to it than an incredulous stare.
} 
to the claim that he is entitled to the money. But of course that's the wrong result. In contrast, the knowledge version of the true account will give us the right result. Since the first person's beliefs about $P$ are all gettiered, they fall short of knowledge. So, by Inquiry, Phenomenon and a distinctively knowledge based version of the true account, he has not attained success in inquiry into $P$ and so, by Reward Entitlement, isn't entitled to the money. The second person's beliefs, in contrast, do qualify as knowledge. In conjunction with Reward Entitlement, the knowledge version of the true account predicts, correctly, that she should get the money. By the same token, there is reason to opt for a distinctively knowledge based version of the true account.

It's now easy to see that one can run an similar argument via Commitment Release. Consider:

The Hire 2. I hire you for up to one month to uncover $P$. On the first day of your appointment, you manage to access a recent DEA report on $P$ which purports to unravel the mystery. With your investigation completed on day 1 , you go on holiday in the Carribean. While you are sipping cocktails in the sun, back home it becomes widely known that the DEA report is a fabrication of a corrupt agent who wanted to climb the career ladder. At the same time, incredible as though this may sound, by an enormous stroke of luck, everything it states about $P$ is true.

The see how the argument will go, just note that if we accept Inquiry, Phenomenon and we analyse understanding along the lines proposed by the true account with the exception that we replace all occurrences of 'knows' by 'justified and/or true belief', Commitment Release entails that you are released from your contractual commitment to uncover $P$. However, again, that's the wrong result. Your contractual commitment is still binding as is evidenced by the fact that I can take steps to get you back to work without negotiating a new contract. In contrast, the knowledge version of the true account does better. Since your beliefs about $P$ are all gettiered, they fall short of knowledge. So, by Inquiry, Phenomena and a distinctively knowledge based version of the true account of understanding, it does not follow that you are released from your contractual commitment. Since the knowledge-based version of the true account is again the only one that does not make mistaken predictions, there is further reason to favour it.

\section{Conclusion}

This paper has looked into the question of the goal of inquiry into both specific questions and general phenomena. It has aimed to make three main points:

First, there is reason to think that knowledge is the goal of inquiry (K-Goal) as, between the four live candidates in the literature on the goal of inquiry into specific questions, only K-goal is empirically adequate.

Second, thinking about the relation between the goal of inquiry into general phenomena and understanding serves to provide further support for my own preferred account of understanding, the true account, vis-à-vis the competition both in the explanationist and the manipulationist camp as the true account can offer the best fit with Inquiry, Phenomenon. 
Finally, the arguments for K-Goal can be adapted to provide support for a distinctively knowledge-based version of the true account.

The news is thus good both for those who think that inquiry aims at knowledge and for champions of the true account.

Acknowledgements Thanks for helpful comments to two anonymous referees and the audiences of the following events: EPSA 2013, University of Helsinki; The Value of Understanding, UFBA, Salvador de Bahia; Wissen, Verstehen, Erklären, University of Dresden; Mathematical Collaboration Workshop II, University of St. Andrews.

Open Access This article is distributed under the terms of the Creative Commons Attribution 4.0 International License (http://creativecommons.org/licenses/by/4.0/), which permits unrestricted use, distribution, and reproduction in any medium, provided you give appropriate credit to the original author(s) and the source, provide a link to the Creative Commons license, and indicate if changes were made.

\section{References}

Davidson, D. (2005). Truth, language and history. Oxford: Clarendon Press. de Regt, H. (2009a). The epistemic value of understanding. Philosophy of Science, 76, 585-97.

de Regt, H. (2009b). Understanding and scientific explanation. In H. De Regt, S. Leonelli, \& K. Eigner (Eds.), Scientific understanding: Philosophical perspectives. Pittsburg, PA: University of Pittsburg Press.

de Regt, H., \& Dieks, D. (2005). A contextual approach to scientific understanding. Synthese, 144, 137-70. Elgin, C. (1996). Considered judgement. Princeton/NJ: Princeton University Press.

Elgin, C. (2006). From knowledge to understanding. In S. Hetherington (Ed.), Epistemology futures. Oxford: Oxford University Press.

Elgin, C. (2009). Is understanding factive? In A. Haddock, A. Millar, \& D. Pritchard (Eds.), Epistemic value. Oxford: Oxford University Press.

Feldman, R. (2000). The ethics of belief. Philosophy and Phenomenological Research, 60, 667-95.

Feldman, R. (2002). Epistemological duties. In P. Moser (Ed.), The oxford handbook of epistemology. New York: Oxford University Press.

Grimm, S. (2006). Is understanding a species of knowledge? The British Journal for the Philosophy of Science, 57, 515-35.

Grimm, S. (2014). Understanding as knowledge of causes. In A. Fairweather (Ed.), Virtue epistemology naturalized. Bridges between virtue epistemology and philosophy of science. Dordrecht: Springer.

Hempel, C. (1965). Aspects of scientific explanation and other essays in the philosophy of science. New York: Free Press.

Hieronymi, P. (2009). Two kinds of agency. In L. O'Brien \& M. Soteriou (Eds.), Mental actions. Oxford: Oxford University Press.

Hills, A. (2016). Understanding why. Nô̂s, 49: 661-688.

Kelp, C. (2014). Two for the knowledge goal of inquiry. American Philosophical Quarterly, 51, 227-32.

Kelp, C. (2015). Understanding phenomena. Synthese, 192, 3799-3816.

Kelp, C. (2017a). Inquiry and the nature of knowledge. Unpublished Manuscript.

Kelp, C. (2017b). Towards a knowledge-based account of understanding. In S. Grimm, C. Baumberger, \& S. Ammon (Eds.), Explaining understanding. New York/NY: Routledge.

Khalifa, K. (2012). Inaugurating understanding or repackaging explanation? Philosophy of Science, 79, $15-37$.

Khalifa, K. (2013). The role of explanation in understanding. The British Journal for the Philosophy of Science, 64, 161-87.

Kvanvig, J. (2003). The value of knowledge and the pursuit of understanding. Cambridge: Cambridge University Press.

Kvanvig, J. (2009). The value of understanding. In A. Haddock, A. Millar, \& D. Pritchard (Eds.), Epistemic value. Oxford: Oxford University Press.

Lipton, P. (2009). Understanding without explanation. In H. De Regt, S. Leonelli, \& K. Eigner (Eds.), Scientific understanding: Philosophical perspectives. Pittsburg, PA: University of Pittsburg Press. 
Lynch, M. (2005). True to life. Why truth matters. Cambridge, MA: MIT Press.

Millar, A. (2011). Why knowledge matters. Proceedings of the Aristotelian Society, Supplementary Volume, $85,63-81$.

Rorty, R. (1995). Is truth a goal of enquiry? Davidson vs. Wright. The Philosophical Quarterly, 45, 281-300.

Rorty, R. (2000). Universality and truth. In R. Brandom (Ed.), Rorty and his critics. Oxford: Blackwell.

Salmon, W. (1984). Scientific explanation and the causal structure of the world. Princeton, NJ: Princeton University Press.

Wedgwood, R. (2002). The aim of belief. Philosophical Perspectives, 16, 267-97.

Wilkenfeld, D. (2013). Understanding as representation manipulability. Synthese, 190, 997-1016.

Williamson, T. (2000). Knowledge and its limits. Oxford: Oxford University Press. 